\title{
Occurrence of NADH-Diaphorases in Isolated Thymus Nuclei
}

\author{
Kiyoshi Ueda, Yoshibumi Nonomura ${ }^{1}$, Takao MatsuUra \\ AND Yoshitsugu Nose ${ }^{2}$ \\ Department of Biochemistry, Kyoto Prefectural University \\ of Medicine, Kyoto (Post No. 602)
}

(Received April 9, 1969)

\begin{abstract}
The significant diaphorase activities which could not be explained by contaminating mitochondria and microsomes are consistently present in isolated calf thymus nuclei. The nuclei seemed to contain at least two apparently different diaphorase activities. Most of the NADH-ferricyanide reductase activity was retained in the nuclei purified by sucrose-gradient centrifugation and sonication. Triton treatment which remove cytoplasmic contaminants and the outer layer of nuclear membrane resulted in no decrease of NADH-ferricyanide reductase activity in nuclear preparation.
\end{abstract}

The means by which cell nuclei obtain free energy for nucleic acid and protein synthesis and other process are important questions to the understanding of cellular physiology and function.

Osawa et al. (1) have shown that thymus nuclei are capable of a net synthesis of ATP under aerobic condition. McEwen et al. (2) have further shown that the mode of nuclear ATP synthesis differs in certain respects from mitochondrial oxidative phosphorylation. These evidences suggest that there is some sort of oxidative enzyme systems within the thymus ouclei. Indeed Yamagata, et al. (3) and Ueda et al. (4) have reported that cytochromes occur in isolated thymus nuclei and presented evidence that their presence is not due to contamination by cytoplasmic constituents. However, relatively little is known of the flavin enzymes involved in the nuclear electron transport system.

In this paper we present preliminary evidence proving that $\mathrm{NADH}$-diaphorases are associated with calf thymus nuclei.

\section{Materials AND Methods}

\section{Separation of Cellular Fractions}

Fresh calf thymus was fractionated by a modification of the method of Allfrey et al. (5). The tissue was minced, homogenized in a Waring blendor with 10 volumes of $0.25 \mathrm{M}$ sucrose- $3 \mathrm{mM} \mathrm{CaCl}{ }_{2}$ (sucrose-Ca solution), and filtered through a sheet of Nylon cloth. The filtered homogenate was centrifuged at $800 \times g$ for $5 \mathrm{~min}$. The nuclear fraction thus obtained was resuspended in the sucrose- $\mathrm{CaCl}_{2}$ medium, filtered and centrifuged as above. The supernatant after sedimentation of nuclei was centrifuged at $1,000 \times g$ for $5 \mathrm{~min}$ and the precipitate was discarded. The mitochondrial and microsomal fractions were then sedimented from the supernatant by centrifugation at $8,000 \times g$ for 15 $\min$ and at $105,000 \times g$ for $60 \mathrm{~min}$ respectively.

\section{Purification of Nuclei}

It was found by electron microscopy that the nuclear fraction was still contaminated by some intact cells and mitochochondria. Following two methods

\footnotetext{
1 Present address: Department of Internal Medicine, Kyoto Prefectural University of Medicine, Kyoto (Post No. 602)

2 上田 潔, 野々村劳文, 松浦尚雄, 能勢善间司
} 
were used for further purification of nuclei.

Method $A \longrightarrow$ The nuclear fraction $(15 \mathrm{ml})$ suspended in $0.25 \mathrm{M}$ sucrose- $3 \mathrm{mM} \mathrm{CaCl} 2$ was layered over $30 \mathrm{ml}$ of $1 \mathrm{M}$ sucrose containing $3 \mathrm{mM} \mathrm{CaCl}_{2}$ and centrifuged in a horizontal rotor at $1,100 \times g$ for 10 min. The pellet was resuspended in sucrose-Ca solution and the layering and centrifugation were repeated. To eliminate the small smount of cytoplasmic contaminant which still attached to the nuclear surface, the nuclei isolated in sucrose-gradients were further treated with sonic oscillation $(10 \mathrm{kc})$ for $10 \mathrm{~min}$, and the sonicate was again layered over $1 \mathrm{M}$ sucrose- $3 \mathrm{mM}$ $\mathrm{CaCl}_{2}$ and centrifuged as described above for $20 \mathrm{~min}$.

Method $B$ - The nuclear fraction was mixed with 2 volumes of $2.3 \mathrm{M}$ sucrose- $3 \mathrm{mM} \mathrm{CaCl}_{2}$. Sucrose concentration of the nuclear fraction was thereby raised to approximately $1.62 \mathrm{M}$, the density of which is just sufficient to float mitochondria and roughsurfaced endoplasmic reticulum. The nuclear fraction layered over $1.95 \mathrm{M}$ sucrose- $3 \mathrm{mM} \mathrm{CaCl}$ and centrifuged at $7,500 \times g$ for $30 \mathrm{~min}$. The pellet formed at the bottom was separated and called " $1.95 \mathrm{M}$ nuclei". For more complete removal of cytoplasmic constituents still attaching to the nuclear surface, $1.95 \mathrm{M}$ nuclei was suspended in sucrose-Ca solution containing $0.25 \%$ Triton X-100, and the suspension was centrifuged immediately to sediment the nuclei. The final pellet of purified nuclei was suspended in sucrose-Ca solution and called "Triton nuclei".

\section{Measurements of Enzyme Activities}

$\mathrm{NADH}$-ferricyanide reductase and NADH-2,6dichlorophenolindophenol (DCIP) reductase activities were assayed at room temperature $\left(25^{\circ}\right)$ in a Shimadzu SV-50A recording spectrophotometer. The sample cell of the spectrophotometer contained NADH 10.2 $\mathrm{mM})$, Tris- $\mathrm{HCl}$ bufler $(0.16 \mathrm{M}, \mathrm{pH} 7.4)$, sucrose $(0.25$ $\mathrm{M}), \mathrm{CaCl}_{2}(3 \mathrm{mM})$, ferricyanide $(0.667 \mathrm{mM})$ and DCIP $(33.3 \mu \mathrm{M})$ and $1-2 \mathrm{mg}$ of enzyme in a final volume of $3.0 \mathrm{ml}$. The control cell contained all the same constituents except for $\mathrm{NADH}$. The reaction was started by addition of $\mathrm{NADH}$ to the sample cell, and the decrease in absorbancy at 420 and $600 \mathrm{~m} \mu$ was recorded.

Cytochrome oxidase (EC 1.9.3.1, ferrocytochrome C: oxygen oxidoreductase) activity was determined spectophotometrically at room temperature by following the oxidation of reduced cytochrome $\mathrm{C}$ at $550 \mathrm{~m} \mu$. The sample cell contained, in a total volume of $3.0 \mathrm{ml}$, reduced horse cytochrome $\mathrm{C}(37 \mu \mathrm{M})$, sucrose $(0.25 \mathrm{M})$, $\mathrm{CaCl}_{2}(3 \mathrm{mM})$, and $1-2 \mathrm{mg}$ of enzyme in $0.16 \mathrm{M}$ Tris$\mathrm{HCl}$ buffer (pH 7.4). The reaction was started by addition of reduced cytochrome $\mathrm{C}$ to the sample cell. The control cell contained all the same constituents exept for reduced cytochrome $\mathrm{c}$ in $3.0 \mathrm{ml}$.
Succinate dehydrogenase (EC 1.3.99.1, succinate: neotetrazolium (NT) oxidoreductase) activity was measured in a reaction system containing sodium succinate $(20 \mathrm{mM})$, neotetrazolium chloride $(2 \mathrm{mM}), \mathrm{KCN}$ (10 mM), Tris-HCl buffer (0.1 M, pH 7.4), sucrose (0.125 M), $\mathrm{CaCl}_{2}(1.15 \mathrm{mM}), 10-20 \mathrm{mg}$ of enzyme in a total volume $2.0 \mathrm{ml}$. After incubation at $30^{\circ}$ for 30 minutes, the formozan produced from the tetrazolium salt was extracted into ethyl acetate, dehydrated with anhydrous sodium sulfate, and the absorbancy was measured at $530 \mathrm{~m} \mu$. The concentration of formozan was calculated by using a millimolar extinction coefficient of 16.7 $\mathrm{cm}^{-1} \mathrm{mM}^{-1}$.

NADase activity was assayed fluorometrically by measuring a decreased amount of NAD as follows: The reaction mixture contained $40 \mathrm{~m} \mu$ moles of NAD, $100 \mu$ moles of potassium phosphate buffer $(\mathrm{pH} 7.0)$ and an enzyme preparation in a total volume of $1 \mathrm{ml}$. After incubation for $15 \mathrm{~min}$ at $37^{\circ}$, the decreased amount of NAD was measured by methylethylketone method (6).

\section{Chemical Analyses}

Protein was determined by the biuret method (7). For determination of phospholipid, RNA and DNA, the sample was fractionated with ethanol-ether $(3 ; 1$, $\mathrm{v} / \mathrm{v}), \mathrm{N} \mathrm{KOH}$, and $5 \%$ trichloroacetic acid, successively, according to the method of Schneider (8). Phospholipid phosphorus was determined in the ethanol-ether extract by the Fiske-SubbaRow method (9), and the phospholipid content was obtained by multiplying phosphorus content by 25. RNA was determined in the alkaline extract by the orcinol method as described by Schneider (8). DNA was estimated in the trichloroacetic acid extract with diphenylamine also by the method of Schneider (8).

\section{Results}

As can be seen from Table 1 , it was found that the specific diaphorase activities in the nuclear fraction amounted to 17 to 19 $\%$ of those detected in the mitochondrial fraction. Such high diaphorase contents in the nuclear fraction could not be explained by contaminating mitochondria, because the specific activity of succinate-NT reductase and cytochrome oxidase in the nuclear fraction were only 3 to $4 \%$ of those in the mitochondrial fraction. However, it was found by electron microscopy that the nuclear fraction thus purified was still contaminated by some intact cells and mitochondria. Further 
TABLE 1

Distribution of oxidoreductase activities in thymus

\begin{tabular}{|c|c|c|c|c|c|c|}
\hline \multirow{4}{*}{ Enzymes } & \multicolumn{6}{|c|}{ Fraction } \\
\hline & \multicolumn{2}{|c|}{ Mitochondrial } & \multicolumn{2}{|c|}{ Microsomal } & \multicolumn{2}{|c|}{ Nuclear } \\
\hline & \multicolumn{2}{|c|}{$\begin{array}{c}\text { Specific activity } \\
\text { memoles } / \text { min } / \text { mg protein }\end{array}$} & \multicolumn{4}{|c|}{$\begin{array}{c}\text { Relative specific activity } \\
(\mathrm{Ms} / \mathrm{Mt}) \times 100 \\
(\mathrm{~N} / \mathrm{Mt}) \times 100\end{array}$} \\
\hline & $m$ & $\sigma$ & $m$ & $\sigma$ & $m$ & $\sigma$ \\
\hline $\mathrm{NADH}_{2}: \mathrm{K}_{3} \mathrm{Fe}(\mathrm{CN})_{6}$ & 1210 & $(224)$ & 45.2 & $(15.6)$ & 17.4 & $(6.5)$ \\
\hline DCIP & 63.8 & $(14.0)$ & 37.1 & $(15.8)$ & 17.8 & (5.3) \\
\hline NT & 5.52 & (2.19) & 35.8 & (1.1) & 19.2 & (9.1) \\
\hline Succ. : NT & 0.51 & $(0.38)$ & 4.7 & $(4.2)$ & 3.0 & $(2.9)$ \\
\hline Cyt. c: $\mathrm{Oe}$ & 56.1 & (21.0) & 3.0 & $(0.2)$ & 4.0 & $(2.2)$ \\
\hline
\end{tabular}

Except for NT reductase, all assays were carried out with a recording spectrophotometer in a total volume $3 \mathrm{ml}$ of $0.25 \mathrm{M}$ sucrose- $3 \mathrm{mM} \mathrm{CaCl} 2$ within $1.67 \times 10^{-2} \mathrm{M}$ Tris-HCl buffer, $\mathrm{pH} 7.4$. For NT reductase assays, the amount of formazan formed at $30^{\circ}$ in the presence of $\mathrm{KCN}$ was determined photometrically after extraction with ethyl acetate.

$\mathrm{m}$ : mean value, $\quad \sigma$ : standard deviation.

purification of nuclei was, therefore, necessary to establish the nuclear localization of diaphorase activities as follows.

The nuclear fraction suspended in sucrose$\mathrm{Ca}$ solution was layered over $1 \mathrm{M}$ sucrose containing $3 \mathrm{~mm} \mathrm{CaCl}{ }_{2}$ and centrifuged as described in method $\mathrm{A}$. The pellet was resuspended in sucrose-Ca solution and layering and centrifugation were repeated. The nuclei thus purified were practically free from intact cells and mitochondria when examined by electron microscopy, although a very small amount of cytoplasmic material was still attached to their surface. They showed a protein/DNA ratio of 1.79 , as compared with the value of 2.04 for the original nuclear fraction. To eliminate the small amount of cytoplasmic contaminant, these nuclei were further treated with sonic oscillation, and the sonicate was again layered over $1 \mathrm{~m}$ sucrose-3

TABLE 2

Enzyme activities in thymus nuclei purified in sucrose gradients

\begin{tabular}{llccc}
\hline \hline Enzymes & $\begin{array}{c}\text { Nuclear } \\
\text { fraction }\end{array}$ & $\begin{array}{c}\text { Nuclei, } \\
\text { over 1 } 1 \mathrm{M} \\
\text { sucrose }\end{array}$ & $\begin{array}{c}\text { Nuclear } \\
\text { particle } \\
\text { sonicated }\end{array}$ \\
\hline & \multicolumn{2}{c}{$\begin{array}{c}\text { Specific activity } \\
\text { mpmoles/min/mg } \\
\text { protein }\end{array}$} & $\begin{array}{c}\text { Relative } \\
\text { concentration } \\
\text { per cent }\end{array}$ \\
$\mathrm{NADH}_{2}:$ & $\mathrm{K}_{3} \mathrm{Fe}(\mathrm{CN})_{6}$ & 211 & 77.5 & 105.1 \\
& $\mathrm{DCIP}$ & 10.4 & 90.6 & 58.0 \\
& $\mathrm{NT}$ & 1.79 & 96.3 & 35.9 \\
Succ. : & $\mathrm{NT}$ & 0.032 & 49.3 & 55.0 \\
Cyt. c $:$ & $\mathrm{O}_{2}$ & 3.13 & 103.4 & 74.2 \\
\hline
\end{tabular}

$\mathrm{mm} \mathrm{CaCl} \mathrm{Ca}_{2}$ and centrifuged as described in purification method A. The nuclei thus treated were considerably damaged morphologically, but seemed to be essentially free from the cytoplasmic material. The protein/ DNA ratio was 1.70 .

As shown in Table 2 most of the NADH diaphorase activities of the original nuclear fraction were still retained in the nuclei purified by sedimentation through $1 \mathrm{~m}$ sucrose, whereas the low activity of succinate-NT reductase was reduced to about $50 \%$. This procedure, however, failed to decrease the cytochrome oxidase activity. It might be possible that nuclei possess a low cytochrome oxidase activity of their own $(10,11)$. Table 2 also shows that further purification of the nuclei by sonication resulted in some increase in NADH-ferricyanide reductase activity. However, the same treatment caused considerable inactivation of both NADH-DCIP and NADHNT reductase activities. Thus nuclei seemed to contain at least two apparently different diaphorase activities.

These observations, though still preliminary, suggested the presence in nuclei of significant diaphorase activities which are not due to mitochondrial contamination. However, since microsomes from this tissue also contained relatively high activities of diaphorase (Table 1), the possibility still remained that the observed diaphorase activities were due to contamination by microsomes. The endo- 
TABLE 3

Enzyme activities in thymus nuclei purified in sucrose gradients and washed with triton $X-100$

\begin{tabular}{ccc}
\hline Enzyme & Microsomes & Triton-nuclei \\
\hline & mumoles $/$ min $/$ mg & Relative specific \\
protein & activity \\
NADH-Ferri & 405.4 & 45.3 \\
NADase & 8.1 & 1.7 \\
\hline
\end{tabular}

plasmic reticulum has been reported to be connected with the outer layer of the nuclear membrane. Therefore, it is perphaps impossible to remove all the microsomal debris from nuclei using purification method A. Triton treatment of nuclei was, therefore, necessary to eliminate the cytoplasmic contaminants and the outer layer of the nuclear membrane. After sedimentation through 1.95 M sucrose-Ca, the nuclei were washed with Triton X-100 as described in purification method B. The contamination by microsomes of purified nuclei was then checked by using NADase as a enzymatic marker of microsomes. It was thus found that the specific activity NADase in the nuclei was very low as compared with that in the microsomal fraction (Table 3), making it improbable that most of the diaphorase activities in the nuclear fractions were due to contaminating microsomes.

\section{Discussion}

The significant diaphorase activities are consistently present in thymus nuclear fractions. However, since cytoplasmic particles from this tissue also contained relatively high activities of diaphorase, the possibility remained that the observed diaphorase activities were due to contamination by cytoplasmic particles. Therefore, cytoplasmic contamination were checked with the activities of marker enzymes. It was found that among the enzymes tested succinate dehydrogenase and NADase were most satisfactory as marker enzymes of mitochondria and microsomes respectively. An estimation based on the activities of marker enzymes indicated that contaminations by mitochondria and microsomes were less than 3 and $2 \%$ respectively, making it improbable that most of the diaphorase activities in the nuclear fractoins were due to contaminating cytoplasmic particles.

It is well known that NADH dehydrogenase is strongly associated with a membrane structure. Therefore, it seems likely that in the nuclei the diaphorases will also be membrane-bound if the diaphorases involve in nuclear electron transport system. Among the diaphorase activities studied in the nuclear fractions, NADH-ferricyanide reductase activity, but not other activities, could be solubilized from nuclear membrane fraction which contained cytochromes. The NADHferricyanide reductase purified catalysed the reduction of cytochrome $b_{5}$ and $c$ by NADH.

It is not yet possible to give any decisive statement concerning the physiological function of nuclear diaphorases. However, previous findings that thymus nuclei contain their own cytochromes and carry out aerobic phosphorylation suggest that the nuclear diaphorases are involved in these activites.

\section{REFFRENCES}

1. Osawa, S., Allfrey, V.G.. Mirsky, A.E., J. Gen Physiol., 40, 491 (1957).

2. McEwen, B. S., Allfrey, V. G., Mirsky, A. E., J. Biol. Chem., 238, 758, 2571, 2579 (1963).

3. Yamagata, S., Ueda, K., and Sato, R., J. Biochem., 60, 160 (1966).

4. Ueda, K., Matsuura, T., Date, N., and Kawai, K., Biochem. Biophys. Res. Comm., 34, 322 (1969).

5. Allfrey, V. G., Mirsky, A. E., and Osawa, S., $J$. Gen. Physiol., 40, 451 (1957).

6. Tabuchi, S., Nisida, K., Nose, Y., and Ueda, K., Vitamins, 27, 303 (1963).

7. Weichselbaum, T.E., Am. J. Clin. Pathol., Tech. Supp., 10, 40 (1946).

8. Schneider, W.C., in "Methods in Enzymology", Academic Press Inc., New York, Vol III p. 680 (1957).

9. Fiske, C. H., and SubbaRow, Y., J. Biol. Chem., 66, 375 (1925).

10. Rees, K. R., Ross, H.F., Rowland, G. F., Biochem. $J ., 83,523$ (1962).

11. Conover, T.E., Fed. Proc., 27, No. 2, 526 (1968). 